\title{
The Politics of Primary Health Care
}

\author{
Malcolm Segall
}

When primary health care (PHC) made its somewhat glittering debut on the world stage in the 1970s, it took on the ambitious role of the agency by which a decent level of health for all peoples would be achieved by the year 2000. Now, well into the penultimate decade of the century, PHC seems to be losing momentum and may be in danger of going the way of its predecessor basic health services (BHS) - in starting as a good idea at the time, but becoming one that is more spoken about than acted upon.

In this article I want to review the politics of this situation, and try to make the case that political factors underlie past failures and may be the key to future successes. To simplify the exposition the discussion will be limited to developing countries, although many of the issues apply also to the developed world. Similarly the argument will be couched mainly in terms of the typical need in developing countries to improve the health of the impoverished rural majority of the population, on the understanding that many of the principles apply also to the urban poor.

\section{Primary Health Care: Its Rise and Fall?}

The PHC approach may be characterised as embodying three basic ideas [Segall 1983a]:

- that the promotion of health depends fundamentally on improving socioeconomic conditions and, in most parts of the world, on the alleviation of poverty and underdevelopment;

- that in this process the mass of the people should be both major activists and the main beneficiaries;

- that the health care system should be restructured to support priority activities at the primary level, because these respond to the most urgent health needs of the people.

The third of these elements is essentially the same as the BHS strategy, although with the knowledge of how inadequately the latter was implemented, there is now a greater concentration on the need to mould the whole health system to support the development of the primary level. While controlling expenditures on large urban hospitals was a recognised corollary of BHS thinking, there was still the tendency to treat the BHS as a separate programme. With PHC came more coherent statements about the need for integrated health sector planning and development, including even consideration of the private sector [Djukanovic and Mach 1975:21-2; WHO/UNICEF 1978:40]. This was an important change of emphasis.

Nevertheless, it was the addition of the two ideas listed first above - asserting the importance of poverty and community participation - as major elements of international thinking on health policy that constituted the qualitative departure of PHC from BHS [Djukanovic and Mach 1975:10-16; WHO/UNICEF 1978:44-52]. These new elements did have their forerunners during the BHS period, and some versions of that model acknowledged more than others the importance of poverty in disease and of seeking community cooperation with health service personnel [see for example King 1966:ch 1]. Yet these factors were never operationalised as central features of the strategy, and the BHS approach was essentially technocratic and indeed often paternalistic: health was something to be 'delivered' to the population by health professionals and their assistants.

In this sense PHC represented a breakthrough in official policy formulation. In international circles, health was now distinguished more clearly as a separate, if related, entity from health care: the former was the product of many factors of which health care was only one, if an important one. What prompted this ideological shift at the beginning of the 1970s? The scientific basis for ascribing importance to socioeconomic factors in health had been established for a long time. Two main reasons for the change may be identified.

One was the evident failure of the BHS strategy to materialise. While there was much talk of extending rural health services through health centres, auxiliary personnel and low-cost technology, practical progress was painfully slow, and resources continued to be channelled disproportionately to expensive hospital 
and medical care for urban minorities, especially the well-off. Meanwhile earlier improvements in life expectancy at birth were slowing down [Gwatkin 1980], and health and nutritional status in the developing world remained very poor, with high morbidity and mortality rates due to largely preventable diseases [for a review of the situation at the time see Office of Health Economics 1972]. There was a growing crisis of confidence in the conventional wisdom about health, and strategists were looking around for 'alternative approaches' to solving the problems.

The second main factor prompting the appearance of PHC was the recognition of the successes of certain practical experiences. Some of these were in capitalist countries, often involving non-government projects that were adopting progressive approaches, particularly with regard to community participation. Yet it would mean a rewriting of the history of that period not to acknowledge that the main demonstration effect came from the national experiences of the developing socialist countries, notably China and Cuba, and especially the former [see for example Djukanovic and Mach 1975; Newell 1975]. In these countries poverty had been greatly alleviated, access to health services had markedly increased, and health and nutritional status had substantially improved. One new feature of these experiences was the organisation of the people through political and social structures. Though some of the accounts at the time may have painted a somewhat idealised picture, descriptions of the health movement in China particularly after 1965 [see for example Horn 1969; Akhtar 1975; Wilenski 1979], and especially the mass campaigns and the barefoot doctors, caught the imagination of world health circles looking for a way out of the apparent impasse.

Primary health care was born as a synthesis of these negative and positive experiences. As a statement of the then 'state of the art' it was a positive contribution, and PHC provided a basis for a fresh attack on the world's mass health problems. Some years on, however, it is all once again proving to be very difficult. To quote an international study which was a follow-up to the original 'Alternative Approaches' study [Djukanovic and Mach 1975] that launched PHC on to the world stage:

... there is often a large gap between PHC plans and implementation: words abound, but concrete results are frequently thin on the ground. What progress there is seems often to be along conventional basic health service lines, sometimes extended in a cheaper version in the form of villagebased health workers. The scope and depth of community involvement are often doubtful. The coordination of health and development planning is often poor and intersectoral health-related activities are frequently rudimentary. Vertical single disease programmes are often not yet integrated with $\mathrm{PHC}$ in practice.

[WHO/UNICEF 1981:48]

Meanwhile the recession is slowing down, wiping out or even reversing per capita economic growth in many parts of the Third World, especially in the poorest countries, with bleak prospects and possibly increasing poverty in the 1980s [World Bank 1980a]. Overall per capita food production in developing countries (excluding China and the other Asian socialist countries) scarcely grew during the 1970s and in many areas (notably in Africa) actually decreased [FAO 1977:4, 1980:79-80]. Earlier increases in life expectancy are slowing down substantially, and in some areas have ceased or have even been reversed [Gwatkin 1980]. According to the latest WHO report on the world health situation: 'As regards the many diseases that plague the less developed count ries, there appears to have been little or no progress in recent years in reducing either their incidence or their prevalence'; some communicable diseases appear to be on the increase, and nutritional deficiencies are widespread and serious [WHO 1980:46].

The reality must be faced that the PHC movement is not yet fulfilling its promise to bring health to the world's peoples, and that the year 2000 , by when 'Health for All' is meant to be achieved, ${ }^{1}$ is approaching fast. What are the obstacles to better progress?

\section{A Political Overview of PHC}

I will now review in turn the three basic PHC themes itemised earlier in order to bring out their political quality. This will not be debated in depth since it is assumed that the experienced reader will be familiar with the issues referred to; my purpose is only to survey the broad political topography of the area.

\section{The political economy of health}

The importance of socioeconomic conditions for health is now well established [see for example McKeown 1979; WHO 1980]. Many health indicators are related to social class or reflections of class (like occupation, income, literacy and housing) at all levels of development [Stewart 1971; Cochrane et al 1978; Preston 1976, 1980:291-3; WHO 1980; Townsend and Davidson 1982]. Life expectancy at birth, for example, correlates closely with per capita income, ${ }^{2}$ a relationship that holds both between countries and within countries.

There have been suggestions that the advent of modern health technology has weakened the relation-

\footnotetext{
Resolution WHA 30.43 of the 30th World Health Assembly, 1977.

2 The relationship is approximately logarithmic with an upper limit to the effect of income above which no further gain in life expectancy is seen [Preston 1976].
} 
ship between income and life expectancy, in the sense that many health problems which previously had to await socioeconomic development can now be dealt with technically [see for example Golladay 1980:1825]. In fact, if anything, the evidence is that mortality reductions in lower income countries became more responsive to rising per capita national income in the 1960s than they had been in the 1930s [Preston 1976]. Two plausible explanations for this are that modern health care is more effective in synergism with higher living standards, and/or that greater national wealth allows the provision of better health care. ${ }^{3}$ Modern health technology has simply meant that greater life expectancies are achieved now for any given level of income, but the relationship between income and life expectancy continues to hold strongly. An estimate has been made that about half the gain in life expectancy achieved by the developing countries between the late 1930s and the late 1960s cannot be explained statistically by increases in per capita income, dietary calorie availability and literacy rates, and it is reasonable to assume that this part of the gain is the result of specific health measures [Preston 1980:304-13]. However, whatever has been the empirical apportionment of responsibility between social and technical factors in health improvements in the past, there is no reason whatsoever to doubt that greater socioeconomic advances would have resulted in greater health improvements or that they would do so in the feature. No amount of technical advance is an argument for underplaying the importance of acting on social conditions to improve health.

Also it is necessary to compare like with like in assessing the relative importance of different health determinants. The increases in life expectancy as a result of modern health technology will have been due, to a considerable degree, to curative measures, especially to the use of anti-infective drugs. While the latter may reduce the transmission of some communicable diseases, the predominant effect of curative care is to aid recovery and prevent deaths from specific disease episodes, rather than decrease the occurrence of ill health. To the extent that health care is curative, its effect in increasing life expectancy does not have the same implications for improved health status as increases in life expectancy resulting from improved socioeconomic circumstances. The latter constitute the ultimate means of primary prevention and reduce the incidence and severity of a range of important nutritional, infective and obstetric conditions, among others. In improved social circumstances people are altogether healthier and that is why they are not dying prematurely.

\footnotetext{
3 The association of higher average per capila national income with better health does not contradict the argument that in most countries a more equitable distribution of income and health care would produce better results still.
}

The struggle against poverty must therefore remain in the forefront of the PHC approach: but what does this amount to? Poverty rarely results mainly from an absolute lack of resources. Its principal causes are social structures that prevent people from working productively, reaping the benefits of their labour, and raising their living standards. The problem is less poverty as such than the structural causes of poverty.

Landless labourers represent a large proportion of the population in many developing countries: in India a third of the population is landless, and several African countries witnessed a considerable growth of landlessness during the 1970s [WHO 1980:27]. In 1975 , a third of the urban labour force and 40 per cent of the total labour force in developing countries (excluding China and the other Asian socialist countries) were unemployed or underemployed [ILO 1976:18]. The international economic situation has greatly worsened for the developing countries. As an illustration, the import of a lorry to Mozambique could be covered in 1975 (the year of the country's independence) by the export of 5.3 tons of cotton, whereas the figure in 1981 was 12.9 tons; between the same two years, the amount of sugar that had to be exported to cover the import of a ton of crude oil rose from $174 \mathrm{~kg}$ to $639 \mathrm{~kg}$ [Frelimo 1983:32]. Facts like these - far removed from those that are usually taught in medical schools - cannot be separated from the quest for better health.

The struggle for health may thus involve a range of actions in the economic, social and political fields, as diverse as for example: the structure of ownership of productive resources; the control of markets and prices; the stimulation of economic and social cooperation among direct producers; the provision to the lat ter of adequate government resources, credit on favourable terms, and access to productive inputs and appropriate technology; and the structure of international economic relations. Does this mean that PHC is synonymous with the whole development process? In a way the answer must indeed be yes, but for practical purposes it needs to have a sharper focus. I believe the PHC approach must involve that (substantial) part of the development process which relates directly to the alleviation of (at least the worst aspects of) poverty in the short term.

Overcoming poverty implies economic growth; yet this is now well recognised to be a necessary but insufficient condition. In the context of (at least a reasonable measure of) growth, the alleviation of poverty means in the first instance a more equitable distribution of income, especially if the latter is understood broadly to include both cash and subsistence income and the 'social wage' (education, health care, and other public services). However, 
income distribution - so often the focus of attention in reforming development strategies - is an insufficient characterisation of the problem, because it does not draw enough attention to the determinants of income. More fundamental is the distribution of the means to generate income: the distribution of productive wealth; and more fundamental still is the distribution of the means to decide on the distribution of wealth and income: the distribution of political power.

It is to cover these basic structural questions that I use the term, 'the political economy of health'. It should be noted that this embraces social issues much more far-reaching than those of 'intersectoral coordination' (involving mainly cooperation among government extension services) that often passes for the socioeconomic or development component of the PHC approach. Important as intersectoral coordination is, it does not begin to cope with the fundamental questions of income, wealth and power, which must be faced if the goal to achieve 'Health for All' during the next 17 years is taken at all seriously.

\section{The scope for popular initiatives}

Community participation has become one of the shiboleths of PHC, which is not surprising given the power of popular involvement in health promotion. One of the attractions of the idea for many governments - and for some international agencies - is the notion that rural communities can be expected to raise their own resources for health care. Even in China, it is pointed out, the commune health system is mainly financed cooperatively. It is important to recognise, however, the context in which that system operates. The economic and social situation of the communes is such that the annual membership contribution to a cooperative medical scheme amounts to only some $0.6-3$ per cent of disposable personal income, and there are also collective welfare funds to cover a proportion of the health expenditures, including the payment of the barefoot doctors and other public health workers [Teh-wei Hu 1976]. Also the central government now allocates a majority of the national health expenditure to the rural areas (preferentially to the poorer ones), subsidising the commune clinics and the county health services that support the commune health system. This is quite different from the typical Third World situation where impoverished rural communities are expected to raise their own health resources, while government (and private) health funds continue to flow disproportionately to provide sophisticated care for the city populations. This is a case of self-reliance and village health workers for the rural poor, and hospitals and medical specialists for the urban rich - all in the name of primary health care. It is not that, in fair circumstances and in proper proportion, communities should not contribute health care resources; doing so is indeed one aspect of their assuming responsibility in this field. But this fact should not let governments 'off the hook' with regard to reshaping the pattern of resource allocation in the health sector to give priority to those in greatest need.

This excessive preoccupation with raising community resources has often displaced attention from the central aspect of popular involvement in health, namely, the people's organised involvement in planning and decision-making on health-related activities. This may be less attractive to governments because it implies a degree of devolution of power, but it is one of the main features distinguishing the PHC from the BHS approach.

Before dealing with the question of power, it should be noted first that deprivation itself exerts a great constraint on popular initiative. There is often the lack of the material means to implement plans, and insufficient education hampers planning and management. Yet beyond these more obvious constraints, one of the most scarce resources in a situation of poverty is time, which must be devoted in the first place to the struggle for survival; but time is needed for the planning, decision-making and implementation of communal activities. One may ask how, for example, women - such important agents for health or disease in a community - carrying the responsibilities for household management and child rearing, and often doing much of the farming, can become effective in the participants health development process in these circumstances.

However, the crux of the problem of popular participation lies in the nature of social relations. This does not refer here to subjective interpersonal relations at the individual level, but to the relationships that develop within the community as a result of the objective positions different people hold in relation to the prevailing power structure. In official mythologies of community participation, communities are portrayed as harmonious homogeneous entities, existing in an unproblematic relationship with governments and even sometimes with the wider economy. But communities are divided and stratified socially, and they exist within the social class st ructure of the national society.

Tenant farmers and landless labourers on the one hand, and landlords on the other, do not have a community of interest such that they can be characterised meaningfully as members of the same community, who happen to perform different roles. Poor homesteaders may well have different community interests from those who hold some capital, and both 
are very likely to have different interests from the owners or managers of large scale commercial farms or plantations. Differential ownership of productive resources creates different class interests, and it confers great influence in community decision-making on those holding economic power. Often overlapping or articulating with these economic power relations is the traditional social structure with its various stratifications. The 'community' is a different place to the mass of local inhabitants than it is to the unelected leaders of this traditional system, with its related social divisions on the bases of age, sex, tribe, region, caste, ethnic origin, and so on.

Not unconnected with these social divisions within communities are the problems in the relationship between such 'communities' and the government. These problems are usually ascribed to the bureaucratic nature of the government machinery and the arbitrary attitudes of local administrators. These can certainly cause real difficulties, but they are an insufficient characterisation of the problem area. The local bureaucrat or policeman, respectively administering and enforcing, for example, the laws on land tenure and wage labour, have an objectively different relationship with tenant farmers and the landless than they do with landlords and landowners, and a different relationship with farm workers than they do with rural employers. These are social relations conditioned by the national political structure. The economic and political relationships in the wider society are present at the community level, mediated by representatives of the dominant national classes and the political machinery, and often articulated with local dominant classes or strata.

Unequal economic and political power are the bases for the divisions in the community, and they are maintained by means of the law and the enforcement agencies. But peaceful social life implies that these coercive means are invoked as rarely as possible, and clothing the iron fist of force is the softer velvet glove of supportive ideologies. These add the cultural dimension to the power nexus, and by mystifying life promote a passive acceptance of the status quo by those on the receiving end of power. In rural communities traditional ideologies are particularly strong and they can exert a highly conservative influence, sometimes even in the face of crude exploitation and oppression. No better example of this can be found than their role in the almost omnipresent subordination of women.

In such circumstances 'community participation' may mean little more than the government obtaining local compliance with its own predetermined plans (including possibly the extraction of community resources) or it might involve allowing the community a voice which is in fact articulated mainly by the loca holders of power, who could well be among the main beneficiaries of participatory exercises [see for example Ahmed 1978:88]. Local leadership of an undemocratic kind can succeed in mobilising populations up to a point, especially for defined projects with a limited time frame (like clinic building or well digging), but it tends to suppress the active and creative involvement of the people in the ongoing planning and implementation of health and development activities [see for example Segall and White 1981].

The struggle for popular participation is basically the struggle for democratisation of decision-making and economic power. To achieve this goal it is usually necessary to have specific social structures - new in most parts of the world - that will provide for the democratic debate and management of community affairs, and will supply the ideological inputs necessary to support the involvement of the presently weaker community members. This is an eminently political process, involving a transfer of power and influence from a minority to the majority at the community level, and it will require a national political process to initiate and foster its development.

\section{Restructuring the health care sector}

Much has been written already about the typical maldistribution of health care in developing countries, with minority urban populations - usually already enjoying better health as a result of higher living standards - benefiting from health care resources per capita very many times greater than the rural poor, who carry a much heavier burden of disease. This maldistribution is usually characterised in simple urban/rural terms, but it should be emphasised that many of the health and health care problems of the rural areas are shared (if generally in lesser measure) by the town poor.

The urban health care takes the form mainly of a combination of government services and the private medical sub-sector. ${ }^{4}$ Health care is available generally to the urban population, and even the private market at its cheaper end may be patronised by the poorer social classes. Nevertheless, the main beneficiaries of the private sub-sector are obviously those who - in the national context and in simple terms - may be said to constitute the urban rich, and they also often have privileged access to the best government facilities and personnel, sometimes by paying (often relatively small) fees. The principal pressure to maintain and

\footnotetext{
4 The discussion here of private medicine will exclude voluntary agencies, traditional practitioners and household self-care. The more complex situation of compulsory health insurance and social security schemes for wage earners, which in many developing countries have some effects similar to those of private medicine, will also be excluded.
} 
develop the level of urban health care thus comes from these main beneficiaries, who also wield the greatest political clout. One mechanism for achieving their goal is political influence on the allocation of government resources; another is pressure in favour of private medicine.

The private medical sub-sector may be substantial in developing countries, in expenditure terms being often as large as, or larger than, the government health services [World Bank 1980b; Preston 1980:340]. The private sub-sector is inherently maldistributive, in that it directs health care resources to those who can pay rather than to those with the greatest need. Nevertheless, a defence commonly put forward by the protagonists of private medicine is that it takes a middle-class load off the government health services, which can then concentrate their efforts on the poor. This argument overlooks, however, the extent to which the private and public sub-sectors intermesh to the detriment of the latter [Segall 1983a]. To itemise some of the effects, the private sub-sector: absorbs scarce government-trained health personnel; practises excessive and expensive curative care, inflating medical costs and drawing on the country's limited foreign exchange for pharmaceuticals and equipment; reinforces the technocratic clinical bias in medical education and influences students' attitudes towards profit-making private practice, thus undermining attempts to orientate health workers towards the PHC approach; and constitutes the independent economic base from which the conservative fraction of the medical profession can oppose structural reforms in the health sector. In addition, the private sub-sector is often not completely financed privately, but receives substantial direct and indirect public subsidies, ranging from the use of health service facilities and personnel at no or below cost, to tax concessions on private health insurance contributions.

The reshaping of the health sector in the direction of PHC inevitably encounters opposition from the main beneficiaries of the existing situation. On the consumer side these comprise, as mentioned, the urban rich, who benefit from superior health care both as individuals and as employers wanting to provide private medical insurance schemes for their workforce. ${ }^{5}$ On the producer side are the health care professionals, especially the doctors, and private capital in the form of the pharmaceutical and medical equipment industries, and those private hospitals and health insurance companies that are profit-making. This is a formidable enough alliance.

Reshaping the health sector for PHC rarely takes the form of the actual redistribution of existing health care

\footnotetext{
5 There are often tax concessions on employers' insurance contributions, which may also be passed on to the general public in higher prices.
}

resources from urban to rural areas. Even where this would be appropriate and there is a legitimate case for rationalisations in urban care, it is usually resisted vigorously and openly, and the political scope for reductions in existing levels of urban service is strictly limited. Reshaping the sector's resource pattern is achieved usually by allocating the bulk of new expenditures to the expansion of rural health care, and here the opposition manifests itself indirectly. Primary health care is never opposed as such: in these days of its orthodoxy it must indeed be supported in theory and there is no reason why it cannot be supported in theory. The practical struggle is over the slicing of the limited 'cake' of new resources. It is the making of competitive demands on these resources to meet other 'urgent needs' in the urban areas, typically of a high technology character, that is the most common form of opposition to PHC reform in the health sector. Unless there is adequate resistance to these demands, a national situation easily develops that PHC is promoted in words, while urban high technology care is supported in deeds. This contradiction is greatly facilitated by the common absence of an accounting and planning system that surveys and organises the health sector as a whole. If the private and public sub-sectors, and the different levels of care, are treated essentially separately - as is still usually the case -the proportional divisions of the total health resource 'cake' are never made apparent, and the contradiction between words and deeds can continue with relative ease [Segall 1983a]. This is surely the story in most countries today, as it was in the days of the BHS strategy.

The success of PHC requires the strictest control on resource allocations both within the health service and - for the reasons given - in any private medical sub-sector as well. With regard to the latter, at least all direct and indirect public subsidies should be removed, and strict limitations will also need to be placed on the sub-sector's growth; indeed some countries have opted for its contraction or abolition. Ownership and control in the health care sector ${ }^{6}$ are thus vital political issues for PHC implementation. Control, however, is not merely a question of public versus private ownership - though it begins with this. A highly bureaucratised government service may be almost as antithetical to PHC as private medicine itself. The issue of control involves also the question of democratisation of decision-making: within the health service generally; between the professionals (especially the doctors) and the so-called subprofessionals (ie the health team approach); and between health service workers and communities and patients. This democratisation will entail struggles against both bureaucracy and elite professionalism. It will also often be necessary to increase the obligations

\footnotetext{
6 The related pharmaceutical sector is dealt with in other articles in
} this Bulletin. 
of health workers to government service and to institute major reforms in medical education. No less than in the areas of political economy and popular involvement, health sector reform for PHC is fraught with a wide variety of conflicting social interests - the stuff of politics.

\section{The Nature of PHC Politics}

From the beginning official international documents identified $\mathrm{PHC}$ as a political issue, that required to be backed by political 'will' or 'commitment' [Djukanovic and Mach 1975:96; WHO/UNICEF 1978:5,42]. This entailed a far more explicit political stance than was ever the case with the BHS strategy, both in the discussion of health problems and in the choice of the national experiences used for their demonstration effect. International political formulations have been in effect exhortations to governments to pursue PHC policies. The UN agencies like WHO are international - not supranational - organisations, and they are subject to the collective decisions of the constituent national governments through their respective governing bodies like the World Health Assembly. Hence UN statements on PHC must be directed towards governments and must ultimately be acceptable to them.

The UN secretariats, however, do have considerable scope for initiative, and they used it to good effect in launching the PHC movement. However, what were progressive political formulations in the 1970s when PHC was still emerging and struggling for international acceptance, may be less so in the 1980 s when it is now part of the conventional wisdom of the international community. The present task in hand is to convert the formal support of the Alma Ata Declaration into actual deeds, and to show results before the end of the century: and that may require a further turn of the political screw.

Primary health care is basically a distributive policy. Not surprisingly, the developing socialist countries have a good record in this respect. This is especially so with regard to the alleviation of poverty (which has been achieved mainly by changes in ownership structure that created opportunities for gainful employment) and to improving access to health services. $^{7}$ They have also notably succeeded in mobilising populations for health, though decisionmaking has often remained too centralised and bureaucratised (while being nevertheless usually a lot more democratic than in the historically preceding

\footnotetext{
This does not mean that health systems in socialist countries are without their problems [see for example Segall 1983b], but the social system is clearly a major determinant of health system development.

${ }^{8}$ On some PHC issues this principle may apply also to socialist countries.
}

situations). At the other extreme, there are som countries with right-wing regimes that will almost certainly block significant progress in a PHC direction. However, there are also non-socialist countries in which more distributive policies are pursued and in which PHC progress may be possible; but in many of them this will depend greatly on the outcome of the contention of social forces for and against. $^{8}$

Primary health care is thus not a painless process, but one that requires persistent pressure to overcome the inevitable opposition forces. This fact should now be made explicit, because the problems will not go away by pretending they do not exist. It is no longer sufficient to limit political formulations to appeals to governments to have a voluntaristic change of heart, as though - even if this happened - it is all that is needed. The more that the necessity for continuing political action against opposition becomes common currency, the more will the struggles of those, both inside and outside governments, who are promoting PHC be legitimated and supported.

\section{Six Areas for Political Action}

It is impossible to generalise about who are, or may come to be, among the main protagonists of PHC in a given situation. This will vary enormously according to political circumstances. They may be the national political leadership, groups within the government, opposition political parties or groups, trade unions, peasants' associations, women's organisations, other non-government organisations, academics, UN agencies, or whoever. The following are some possible lines of action that these protagonists may individually or severally pursue. The selection is not intended to be exhaustive but is only indicative, and priority actions are likely to change over time.

\section{Develop the science and practice of social epidemiology}

The key issue here is the demonstration and quantification of social inequalities in health and health care.

Epidemiology concerns the population aspects of ill health. Classically its point of departure is a disease or health problem (like tuberculosis or coronary heart disease or infant mortality). The tasks of epidemiology are then to analyse its frequency and distribution in the population, to identify associated factors (biological, environmental, social or other) that may be important in the causation with a view to discovering means of control, and to evaluate the impact of interventions on therates of occurrence. Epidemiology is the basic science of public health, yet in this most common classical form it is (necessary but) insufficient 
for PHC purposes. Starting as it does with the individual condition, it does not identify adequately how a range of different health problems may be concentrated in certain social classes or groups. Though collectively individual epidemiological studies may point to a social clustering of disease, they do not characterise the clustering or the full range of links between the different problems systematically. This is the role of social epidemiology. Its point of departure is not the disease but the social group. It establishes the group's broad health experiences and analyses their association with various facets of social experience, thus identifying the problems in a way that calls for social interventions. Social epidemiology is thus the basic science to underpin the distributive goals of the PHC approach. Classical epidemiology remains the science of the individual PHC component programmes (like those for communicable disease control), but social epidemiology provides the data base for the structural PHC reforms that will create the conditions for those programmes to be implemented.

The basic task of social epidemiology is to demonstrate and quantify social inequalities in health. This is now an established procedure in some developed countries [see for example WHO 1980:4750]. In Britain, for example, it has been shown that mortality experience generally deteriorates with falling social class ranking, and that such a class 'gradient' can be observed for the majority of causes of death; morbidity tends to show a similar class distribution, especially with chronic illnesses [Townsend and Davidson 1982: ch 2].

Very few quantified data of this kind are available for developing countries, and there is a pressing need to close this information gap. One problem naturally lies in the generally deficient health information systems, but possibly more critical are the simple lack of awareness of the social epidemiological approach and its uses, and the consequent lack of familiarity with its methods and data needs. In fact the inequalities in health in developing countries are very great, and this allows the broad picture to be painted with relative ease. For practical purposes it may be that, at least in the first instance, only three main social groupings are required: the urban rich, the urban poor, and the rural poor, and there are often enough health data (or they can be compiled without an impossible effort) to characterise the health experiences of these groups (or proxies for them) with reasonable accuracy [see for example Segall 1983a]. Epidemiology can also be applied to health services, and social epidemiology is the basic method to demonstrate and quantify the social maldistribution of health care, showing also how this often compounds the social inequalities in health.
Social epidemiology can be powerful instrument in support both of political action for PHC and of the technical planning and programming necessary to implement the distributional aspects of the approach (see 2 and 5 below). The science and practice of social epidemiology should be greatly expanded in developing countries. It should be adapted to their conditions and resource constraints, and health information systems should be developed to serve its data needs.

\section{Popularise social epidemiological findings and the PHC approach}

Continuing political support for PHC implies that knowledge of the relevant issues should not remain the elite preserve of government officials, academics and UN representatives; behind closed doors opposition forces are likely to wield more persuasive influence and to prevail. The more the facts about the inequalities in health and health care, and the principles of PHC, are shared with the mass of the people who stand to benefit - the more the issues become part of the popular consciousness - the easier it will be to build up the head of political pressure to see the policy through. Every effort should be made to propagate $\mathrm{PHC}$ facts and issues in a simple form, and to use all the means of mass communication (for the literate and illiterate) to mount a sustained campaign of popular education.

The quantified findings (crude as they may be) of social epidemiological studies will be valuable in this context. For example, to know for your country the incomes of the urban rich and the rural poor (which might work out to be in a ratio of, say, 40 to 1 ), their respective child mortality rates (which could be in a ratio of, say, 1 to 40 ), and the per capita health care expenditure from which the two groups benefit (which might again be in a ratio of 40 to 1 ), has much more impact than general statements such as that poverty is a cause of disease and the rich get better health care than the poor - observations already made by most people.

A special education campaign should be mounted for health workers, especially for the professionals, and most especially for the doctors. A classical medical education (perhaps with a few more token hours of 'community medicine') is still the norm in most countries. This type of training, together with the reality that curative practice is what most health personnel presently do most of the time, tends to narrow the vision of health workers to the traditional clinical relationship, and this can make it more difficult for them to open their minds to the broader aspects of the PHC approach, notably to the question of community and patient involvement in decisionmaking. It is true that many professionals cannot 'understand' PHC because (at whatever level of their 
consciousness may be involved) they do not want to understand. Their present bread and butter - with not a little jam - depends on the existing medical system. These are the fraction of the health professionals who constitute part of the opposition. However, there are also a growing number of professionals, especially among the younger generations, who are coming to see the relevance of PHC to the social value of their work, and who are prepared to respond to the career consequences of the approach. It is important to provide these professionals, and all health workers, with the information they need for the development of their social consciousness and for their own work in the propagation of PHC ideas. The battle for a PHC consciousness should be carried into the ranks of the health professions; their voice carries political weight and their cooperation is needed for the technical implementation of PHC.

\section{Feed PHC policy into the organisations of the common people}

Popular consciousness is one thing, and political clout is another. It is important that organisations representing the interests of the mass of ordinary people - be these political parties (in power or in opposition), trade unions, peasants' associations, women's organisations, or religious groups - should take up the cause of PHC. The spontaneous popular demands about health are usually for more doctors and hospitals, and this is normally reflected in the political demands of mass-based organisations. While these demands for better medical care are likely to be quite justified, they should be located in the broader context of the PHC approach. The leadership of mass organisations should be convinced about the correctness of the approach, so they can use their influence to get this message across to their members and constituencies, and use the weight of their organisations in the political arena to support struggles for PHC. They are likely to be particularly supportive of the $\mathrm{PHC}$ elements relating to the alleviation of poverty and to the democratisation of decision-making. As this point is illustrated so well in the article by Macêdo and Vieira on Brazil included in this Bulletin, no further discussion need be undertaken here.

\section{Legislate wherever possible}

Political pressure for change is one thing, and the force of law is another. As and when a government is persuaded to undertake a particular PHC reform, it is good practice to get it on the statute book wherever possible. A law is not automatically implemented, and it can always be revoked. It is not therefore a substitute for continuing pressure to turn PHC policy into reality, but it does strengthen the base from which such pressure is applied. In addition, the opposition may lose some support once the apparent fait accompli of legislation is effected. Thus legislative measures are among the means by which political PHC gains can be given an element of stability.

Without prejudging at this point how tough any particular law may be, the following are some areas where PHC-related legislation may be called for:

- economic and fiscal reform relating to the distribution of wealth and income;

- establishment of social structures and processes for the democratisation of decision-making;

- establishment of a national health service;

- definition of the scope of any private medical subsector(s);

- educational definitions of health professionals, bonding of graduates to government service, and criteria for career advancement;

- pharmaceuticals and medical equipment.

\section{Establish health planning means to serve distributional ends}

The key issue here is planning on the criterion of social equity.

Health planning procedures should support the distributional aims of PHC. Given the inertia of entrenched planning methodologies, the establishment of appropriate methods may itself be a political task. While the distributional principles apply to all the health-related sectors, the discussion will be limited here to the health care sector itself.

The conventional public health planning prevalent in developing countries is based on the traditional medical approach of classical epidemiology. It identifies individual or grouped health problems and designs specific health care programmes to resolve them, like those for communicable disease control, immunisation, or mother and child health. While this is a perfectly necessary activity it is insufficient for PHC purposes; it is health care programming, which should not be confused with PHC planning in the strategic sense.

Where health care programming is the predominant planning methodology, it tends to 'verticalise' health care activities into distinct national programmes which can become complex and unwieldy. Despite being nominally PHC components, these programmes tend to develop a life of their own and reproduce many of the problems of the vertical campaigns that characterised the period before the BHS strategy. Integration of component programmes into a coherent PHC structure is a continuing problem in many countries. This is one symptom of the general 
problem that health care programming does not deal adequately with the restructuring of the health sector necessary for PHC and therefore for the success of the health care programmes themselves. Without that restructuring and the concomitant allocation of resources to priority areas, the programmes will remain chronically short of funds - the common situation at present. Health care programming does not relate to a high enough level of decision-making, and does not service the political process with the information and proposals necessary for strategic PHC policy formation; indeed it does not have the planning 'vocabulary' to do so.

Primary health care requires a planning method that has - like social epidemiology - its point of departure in deprived social classes; it can then have 'horizontal' distributional goals built into it as an inherent characteristic. The key task is to restructure the health sector so that resources are channelled preferentially to those with the greatest need, that is, according to the principle of social equity; and the key instrument to achieve this is therefore the control and planning of resource allocation. Resource planning must be the leading planning method for PHC reform in the health sector. For the reasons discussed earlier, it should treat the sector holistically, looking not merely at the primary level itself, but at the higher levels of the government service and at any private medical sub-sector(s) as well.

Starting from the existing inequalities in health care and health status identified through social epidemiological studies, the prime task is to plan their systematic reduction through the differential allocation of resources, particularly by geographical area (notably with an urban/rural breakdown) and by level of care. Strengthening the structures and increasing the resource availability in rural districts create the conditions for the bulk of health care programming to be done on a decentralised basis, by people in contact with the local circumstances. This decentralised 'horizontal' approach also facilitates local intersectoral cooperation, and political and popular involvement. Increasingly national programming can consist of the supervision and coordination of local health care programmes, while the central planning role remains the promotion of social equity through resource allocations.

The resource approach to $\mathrm{PHC}$ planning represents a considerable methodological departure from the common practice in developing countries, and even from that of WHO, whose 'managerial process for national health development' [WHO 1981] - itself derived from the earlier procedure of country health programming - is basically a systematic variant of health care programming and has not yet absorbed the full planning implications of the PHC approach. This subject, as well as how PHC resource planning should articulate with health care programming, has been discussed in detail elsewhere [Segall 1983a]; only this brief outline of principle is given here.

\section{Press for international economic action}

The necessity for national actions to alleviate poverty - part of the PHC approach itself - cannot be separated from the need for economic change internationally, especially in this period of recession. Economic recession is not a natural phenomenon (as it is often portrayed), but arises out of a specific economic system and is conditioned by specific economic policies. It is hypocritical for the Western industrialised countries to claim to support the PHC approach in developing countries when, in the context of providing relatively small amounts of health sector aid, amounting from all sources to about 3 per cent of the total health expenditures by developing countries [Preston 1980:315], their economic policies are wiping out development efforts in many parts of the Third World, with the consequent perpetuation or exacerbation of poverty and ill health.

A vigorous campaign affirming the deleterious effects of poverty on health and stating unequivocally how they radically undermine the $\mathrm{PHC}$ approach, should be carried into the international fora where the world economy is debated. This campaign should be prosecuted, not merely by the developing countries themselves, but especially by the UN agencies most closely associated with PHC, namely, WHO and UNICEF. The PHC movement should not be allowed to provide a smokescreen for the grave effects of the present economic situation on world health. International agencies should staunchly support the calls for a reordering of the world economy, and for measures to counteract the recession and its effects on the Third World.

\section{Summary and Conclusions}

All three main elements of the PHC approach - the alleviation of poverty, popular involvement, and health sector reform - are fraught with issues of conflicting social interests, which explain the present slow pace of progress in most countries. The political character of PHC should now be made more explicit to legitimate and support the struggles of PHC protagonists to see official words translated into actual deeds. The year 2000 is approaching fast. Six lines of action are discussed; there will be others. 


\section{References}

Ahmed, M., 1978, 'Community participation, the heart of primary health care', Assignment Children, vol 42, pp 80-99

Akhtar, S., 1975, Health Care in the People's Republic of China, a bibliography with abstracts, IDRC-038e, International Development Research Centre, Ottawa

Cochrane, A. L., A. S. St. Leger and F. Moore, 1978, 'Health service "input" and mortality "output" in developed countries', Journal of Epidemiology and Community Health, vol 32, pp 200-5

Djukanovic, V. and E. P. Mach (eds), 1975, Alternative Approaches to Meeting Basic Health Needs in Developing Countries, a joint UNICEF/WHO study, WHO, Geneva

FAO, 1977, Fourth World Food Survey, FAO statistics series no 11, FAO food and nutrition series no 10, FAO, Rome -1981,1980 FAO Production Yearbook, vol 34, FAO statistics series no 34, FAO, Rome

Frelimo, 1983, 'Directivas económicas e sociais', published in Tempo, no 662, Maputo, pp 29-36

Golladay, F., 1980, 'Health problems and policies in the developing countries', Staff Working Paper no 412, World Bank, Washington DC

Gwatkin, D. R., 1980, 'Indications of change in developing country mortality trends: the end of an era?', Population and Development, vol 6 no 4, pp 615-44

Horn, J. S., 1969, Away with All Pests, Paul Hamlyn, London

ILO, 1976, Employment, Growth and Basic Needs: a OneWorld Problem, Praeger Publishers, New York/London

King, M. (ed), 1966, Medical Care in Developing Countries, Oxford University Press, Nairobi

McKeown, T., 1979, The Role of Medicine, Basil Blackwell, Oxford

Newell, K. W. (ed), 1975, Health by the People, WHO, Geneva

Office of Health Economics, 1972, Medical Care in Developing Countries, OHE paper no 44, London
Preston, S. H., 1976, Mortality Patterns in National Populations, Academic Press, New York, ch 4

-1980 , 'Causes and consequences of mortality declines in less developed countries during the twentieth century' in R. A. Easterlin (ed), Population and Economic Change in Developing Countries, National Bureau of Economic Research, University of Chicago Press, Chicago and London

Segall, M. M., 1983a, 'Planning and politics of resource allocation for primary health care: promotion of meaningful national policy', Social Science and Medicine, vol 17 no $24,1947-60$

$-1983 \mathrm{~b}$, 'On the concept of a socialist health system', International Journal of Health Services, vol 13 no 2, pp 221-5

-and A. White, 1981, 'Research on primary health care: a multidisciplinary project in Ghana', World Health Forum, vol 2 no 3, pp 341-6

Stewart, C. T., 1971, 'Allocation of resources to health', The Journal of Human Resources, vol VI no 1, pp 103-22

Teh-wei Hu, 1976, 'The financing and the economic efficiency of rural health services in the People's Republic of China', International Journal of Health Services, vol 6 no 2, pp 239 49

Townsend, P. and N. Davidson (eds), 1982, Inequalities in Health: the Black Report, Penguin Books, Harmondsworth, Middlesex, England

WHO, 1980, Sixth Report on the World Health Situation, part I, WHO, Geneva, ch 2 and 3

- 1981, Managerial Process for National Health Development, WHO, Geneva

WHO/UNICEF, 1978, Primary Health Care, report of the international conference at Alma Ata, WHO, Geneva - 1981, National Decision-making for Primary Health Care, a study by the UNICEF/WHO joint committee on health policy, WHO, Geneva

Wilenski, P., 1979, The Delivery of Health Services in the People's Republic of China, IDRC-056e, International Development Research Centre, Ottawa

World Bank, 1980a, World Development Report. 1980, World Bank, Washington DC

-1980b, Health Sector Policy Paper, World Bank, Washington $\mathrm{DC}$, annex 7 